\section{Minutes of Annual Neurocritical Care Update 2017}

\section{Ashish Chakravarty, Saurabh Anand}

The Annual Neurocritical Care Update 2017 (ANCU 2017) was held on the $24^{\text {th }}$ and $25^{\text {th }}$ March 2017 at Artemis Hospital, Gurgaon. It was organised by Artemis Agrim Institute of Neurosciences under the aegis of Indian Society of Neuroanaesthesia and Critical Care and Indian Academy of Neurology. Dr. Saurabh Anand was the organising chairman, and Dr. Ashish Chakravarty was the organising secretary. The diligently worked out scientific program of this conference brought advances in the neurocritical care to the forefront as we welcomed a record number of registered attendees from all corners of the globe to demystify the mystery behind the subject. We shifted the main focus from dreary and didactic lectures to sessions where we interact, question, debate and demonstrate to innovate and thus, evolve ourselves. For the first time, a conference in neurocritical care was going live for full 2 days. For increasing the reach of our conference to every small corner of the country we tied up with Curofy which has got the largest number of verified doctors. Hence, those people who were not able to attend our conference got the opportunity to listen to the experts and also ask questions online live with the help of Curofy app.

It was attended by 200 delegates from all over India and abroad and subscribed online by another 250 delegates. ANCU was granted $14 \mathrm{CME}$ hours by the Delhi Medical Council. The registration for the event began at 8:00 am on the $24^{\text {th }}$ March. The welcome speech was delivered by the organising chairman followed by lamp lighting ceremony and formal inauguration at 8:30 am by Dr. Colleen Moran (USA) and Dr. Vijay Sharma (Singapore). The conference started with a session on 'Trauma' which include lectures on 'BTF guidelines 2016-Can we leave the past behind?' ,'Hypothermia in Neurocritical Care Unit:

Department of Neuroanaesthesiology and Neurocritical Care, Artemis Hospital, Gurgaon, Haryana, India

Address for correspondence:

Dr. Saurabh Anand, Department of Neuroanaesthesiology and Neurocritical Care, Artemis Hospital, Gurgaon, Haryana, India. E-mail: doctoranand@yahoo.com
To cool or not to cool?' and 'Nonconventional Ventilation strategies in Cervical Spine injury: Breaking stereotypes', delivered by Dr. Prasanna Bidkar (Puducherry), Dr. Colleen Moran (USA) and Dr. Rajesh Chawla (New Delhi), respectively. This was followed by a session on 'Stroke' in which Dr. Vijay Sharma (Singapore) discussed on 'Why is Protocolised Management an absolute necessity in Stroke - How we do $i^{\prime}$ '. This was followed by a lecture on 'Stop the ooze!! Newer antiplatelets and anticoagulants' by Dr. Rajsrinivas Parthasarathy. In the interactive session that followed, Dr. Saurabh Anand (organising chairman) and Dr. Sumit Bajaj (Gurgaon) presented 'Critical Care Issues in Stroke and $\mathrm{ICH}^{\prime}$ where the emphasis was on how to manage the blood pressure in these scenarios. 'Rubik's Cube' session consisted a bag of miscellaneous issues in neurocritical care such as 'Critical Care Issues in Pituitary adenoma' by Dr. Devendra Gupta (Lucknow), 'Intensive care issues in Guillain-Barré syndrome: practice essential' by Dr. Sandeep Dewan (Gurgaon) and 'Hyponatremia simplified - Understanding Sodium' by Dr. Radhakrishnan M (Bengaluru). 'Ask the Expert' was another interactive session in which Dr. Sweetha Mohan (Gurgaon) discussed 'Super refractory status epilepticus' moderated by Dr. CB Rathore (Vadodara) and Dr. Jeetendra Sharma (Gurgaon). This was followed by a panel discussion on 'Declaring Brain Death -Current Scenario, Legal and Organizational changes to improve organ donation in India'. The panel discussion was moderated by Dr. V Ponniah (Chennai) and comprised panellists such as Dr. Shrikanth Srinivasan (Gurgaon), Dr. Vikram Barua (Gurgaon), Dr. Vinay Goel (New Delhi), Dr. Aditya Gupta (Gurgaon) and Dr. Virendra Jain (Gurgaon). This was followed by a speech of $5 \mathrm{~min}$ by the CEO of Artemis Hospital Dr. Devlina Chakravarty in which she emphasised on organ donation and welcomes all delegates and faculty to the event. A quick lunch thereafter, was followed by hands-on workshops on transcranial Doppler (TCD) and Advanced Airway Workshop. The TCD workshop was unique in that it was the first of its type to be conducted in Delhi and National Capital Territory region. This was conducted under the able guidance of Dr. Vijay Sharma (Singapore), an internationally acclaimed authority in the field of stroke neurology. Dr. Amit Batra (New Delhi) and Dr. GP Rath (New Delhi) also helped in hands-on workshop of TCD.

Each of the workshops was conducted over $4 \mathrm{~h}$ and provided ample opportunity for the candidates to observe, interact, learn and evolve, thus living up to the motto of the scientific meet. After a heavy day, the 
esteemed faculty let their hair loose at the Faculty Dinner organised at the Ramada Central Gurgaon.

Second day of the conference started at 8:00 am with 'Sepsis: Fighting the bugs' which witnessed stalwarts in the field such as Dr. Yatin Mehta (Gurgaon) delivering a lecture on 'Candidemia in ICU - Let's do it right!' and Dr. Sumit Ray (New Delhi) speaking on 'Empirical therapy in Sepsis - Current controversies'. Both of them end up answering many queries of online questions of the audience as well. The second session was a case-based interactive one on 'Sepsis-induced acute kidney injury' presented by Dr. Priyanka Garg (Gurgaon) and moderated by Dr. Manju Aggarwal (Gurgaon) and Dr. Suneel Garg (New Delhi). Given the magnitude of the problem in Intensive Care Units (ICUs) around the globe, the next session was again based on sepsis, in which Dr. V Pooniah (Chennai) and Dr. Colleen Moran (USA) shared their views on 'Controversies in diagnosis and prevention of ventilator-associated pneumonia' and 'Developing a Fever Management Programme in Neurocritical Care Unit', respectively. This was followed by two interactive sessions, namely, 'Meningitis-How to approach' presented by Dr. Pratibha Kujur (Gurgaon) and Dr. Amit Agarwal (Gurgaon) and moderated by Dr. Sumit Singh (Gurgaon), and 'Subarachnoid Hemorrhage' in which Dr. Hemant Bhagat (Chandigarh) and Dr. Saurabh Anand (organising chairman) dwelt on 'Monitoring in poor grade subarachnoid haemorrhage and management of delayed cerebral ischaemia (DCI)' followed by a brief lecture on 'Endovascular Management of DCI' by Dr. Vipul Gupta (Gurgaon). The debate session that followed was unique in that for each topic a pre-debate and a post-debate poll was conducted to see how the debates changed the view of the audience. The topics included were 'Daily interruption of sedation in Neurocritical Care' debated upon by Dr. Keshav Goyal (New Delhi) and Dr. Monica Tandon (New Delhi), 'Is the Era of colloid over in ICU' debated upon by Dr. Anil Parakh (Mumbai) and Dr. Saurabh Bhargav (Jaipur), 'Decompressivecraniectomy in TBI' debated upon by Dr. Prasanna Bidkar (Puducherry) and Dr. Aditya Gupta (Gurgaon) and 'Does Multimodal Monitoring make a difference in Neurocritical care?' debated upon by Dr. Manish Marda (New Delhi) and Dr. Ashish Bindra (New Delhi). The last interactive session of the last day was based on a burning and yet quite often neglected the issue of 'Reducing cost in the ICU' presented by Dr. Kavita Sandhu (New Delhi) and Dr. Ashish Chakravarty (organising secretary). Each of the sessions was followed by $15 \mathrm{~min}$ of active discussion on both the days. While the discussions were going on in the auditorium, free paper presentations were carried out from 11:30 am to 1:00 pm. A total of eighteen papers were selected for podium presentation. Names of the winners of the free papers were announced at the end of the lecture sessions on the $2^{\text {nd }}$ day before wrapping up for lunch. The post-lunch workshop sessions on ‘Point of Care USG in ICU' moderated by Dr. Shrikanth Srinivasan (Gurgaon) and 'Neuroradiology for the Intensivists' moderated by Dr. Tariq Matin (Gurgaon). All the workshops were attended by large number of delegates with a lot of zeal. The conference concluded with a vote of thanks by Dr. Ashish Chakravarty (organising secretary).

\section{Financial support and sponsorship}

Nil.

\section{Conflicts of interest}

There are no conflicts of interest.

This is an open access article distributed under the terms of the Creative Commons Attribution-NonCommercial-ShareAlike 3.0 License, which allows others to remix, tweak, and build upon the work non-commercially, as long as the author is credited and the new creations are licensed under the identical terms.

\begin{tabular}{|l|l|}
\hline \multicolumn{2}{|c|}{ Access this article online } \\
\hline Quick Response Code: & Website: \\
\hline & www.jnaccjournal.org \\
\cline { 2 - 2 } & \\
\hline
\end{tabular}

How to cite this article: Chakravarty A, Anand S. Minutes of Annual Neurocritical Care Update 2017. J Neuroanaesthesiol Crit Care 2017;4:132-3. 